\title{
Pigmented Villonodular Tenosynovitis of the Temporomandibular Joint-A Case Report
}

\author{
Satinder Singh*, Iram Khan, Shalabh Sharma, Asish K. Lahiri \\ Department of ENT, Sir Ganga Ram Hospital, New Delhi, India \\ Email: "satindersingh123@rediffmail.com
}

Received 22 November 2015; accepted 26 January 2016; published 29 January 2016

Copyright (C) 2016 by authors and Scientific Research Publishing Inc.

This work is licensed under the Creative Commons Attribution International License (CC BY). http://creativecommons.org/licenses/by/4.0/

(c) (i) Open Access

\begin{abstract}
Background: Pigmented villonodular synovitis is a rare condition typically affecting the major joints and the involvement of the temporomandibular joint is rare. Although, it is histologically benign, it can be locally aggressive, capable of extensive bone destruction. The disease has aggressive behavior and a high incidence of recurrence $(40 \%-60 \%)$. Case report: A 35 years old male presented with history of unilateral hearing loss and otalgia of six month duration. On examination, there was a soft bulge in the superior wall of external auditory canal. Contrast enhanced CT scan showed soft tissue density occupying the right external auditory canal and bulging into the middle ear cavity, displacing the intact ossicular chain medially with evidence of destruction of the posterior wall of the external auditory canal, glenoid fossa, mastoid bone and the scutum. The squamous part of the right temporal bone showed evidence of lateral bowing with discontinuity. Surgical resection was done through post aural approach. Histopathological examination revealed pigmented villonodular tenosynovitis which stained positive for CD 68. Post operatively patient was evaluated clinically and with radiological modalities which showed healthy mastoid cavity and no increase in post operative granulations on magnetic resonance imaging. Conclusion: Pigmented villonodular tenosynovitis of temporomandibular joint is a rare entity. Due to the aggressive behavior of the lesion, radical or aggressive surgical resection should be done. Long term follow up with radiological modality should be done due to the high recurrence rate.
\end{abstract}

\section{Keywords}

Pigmented Villonodular Synovitis, Temporomandibular Joint, Giant Cell Granuloma, Synovitis

\section{Introduction}

Tenosynovitis is a rare lesion, typically monoarthric, which primarily affects the major joints. Chassaignac was "Corresponding author.

How to cite this paper: Singh, S., Khan, I., Sharma, S. and Lahiri, A.K. (2016) Pigmented Villonodular Tenosynovitis of the Temporomandibular Joint-A Case Report. International Journal of Otolaryngology and Head \& Neck Surgery, 5, 34-37. http://dx.doi.org/10.4236/ijohns.2016.51006 
first to describe the lesion in 1852 [1], but it was Jaffe et al. in 1941 [2] who first introduced the term pigmented villonodular tenosynovitis. Jaffe revealed that various lesions of hand and joint with their differing gross morphologies are variants of the same disorder. PVNS usually presents as preauricular mass with locally destructive features which may lead to incorrect diagnosis of parotid tumor. The lesion arising in temporomandibular joint is exceedingly rare with only few cases having being reported in literature so far. Although, it is histologically benign, it can be locally aggressive, capable of extensive bone destruction. CT scan is helpful in defining the extent of bone erosion, while MRI is considered the best imaging modality especially during post-operative follow up which is recommended for a period of seven to eight years [3]. Due to the aggressive behavior of this lesion, the $40 \%$ - $60 \%$ incidence of recurrence aggressive surgical resection with long term follow up with imaging is necessary. Herein, we report a rare case of PVNS presenting as aural mass with local destruction of temoromandibular joint and mastoid.

\section{Case Report}

A 35 years old male presented with pain and decreased hearing in the right ear of 6 months duration. The examination of the right ear showed mass filling whole of external auditory canal. Patient did not have any facial swelling or facial weakness. Pure tone audiometry showed $45 \mathrm{db}$ conductive hearing loss in right ear. Contrast enhanced CT scan showed soft tissue density occupying the right external auditory canal and bulging into the middle ear cavity, displacing the intact ossicular chain medially. There was evidence of destruction of the posterior wall of the external auditory canal, glenoid fossa, mastoid bone and the scutum. The squamous part of the right temporal bone showed evidence of lateral bowing with discontinuity. There was complete destruction of anterior wall of external auditory canal. However the mandibular condyle seemed uninvolved (Figure 1).

Based on these finding, patient underwent post aural mastoid exploration under general anaesthesia. Dirty brown tumor was seen involving the superior canal wall, glenoid fossa, mastoid bone and middle ear, which were cleared. Superiorly and posteriorly, the involved part of the squamous temporal bone was removed till the normal healthy bone and middle fossa dura was encountered. Histopathological examination revealed multiple osteoclastic multinucleated giant cells in a fibro connective stroma (Figure 2(a)). Histiocytes, which were hemosiderin laden, stained positive for CD 68 (Figure 2(b)).

Post-operative CT scan showed granulations in the external auditory canal and the middle ear cavity. Patient was followed up with serial MRIs done at 3 months, 6 months and one year postoperatively, which did not show any change and clinically the mastoid cavity is well healed without any sign of pathology.

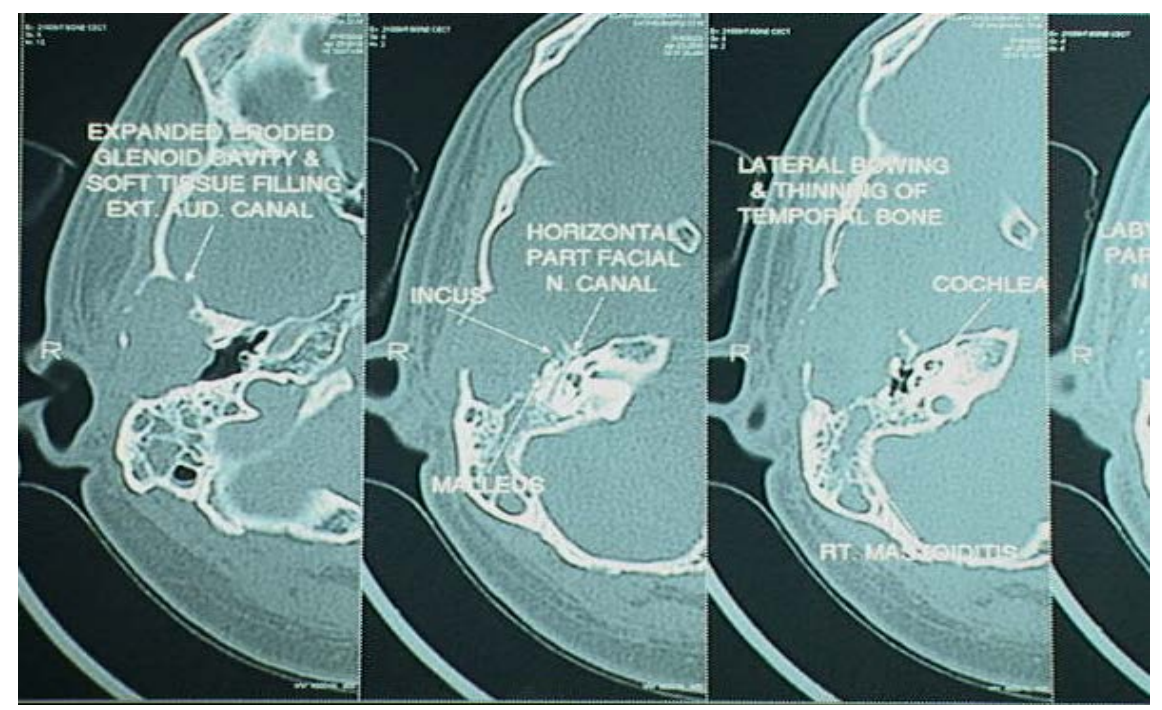

Figure 1. A computerized tomography scan, axial cut shows the soft tissue density involving the right superior canal wall, attic, tegmen which was partially eroded and extending to the external auditory canal. Lateral bowing and thinning of the temporal bone is also seen. Soft tissue is also seen occupying the mastoid air cell system on the right side. This was the preoperative CT scan of the patient. 


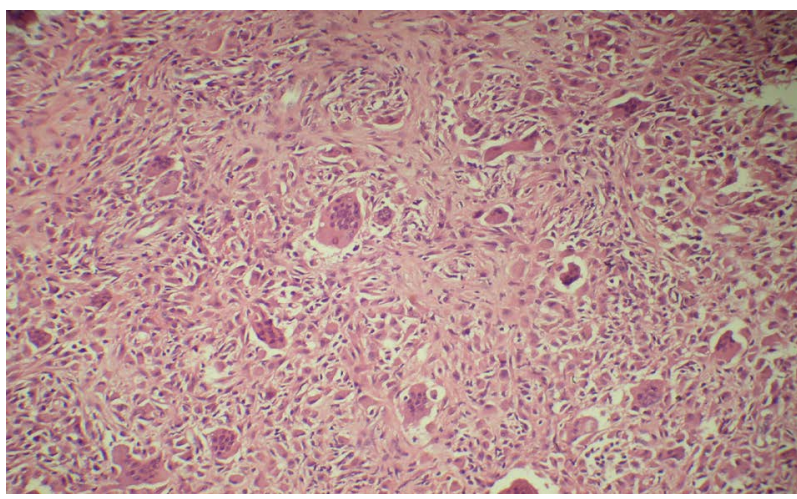

(a)

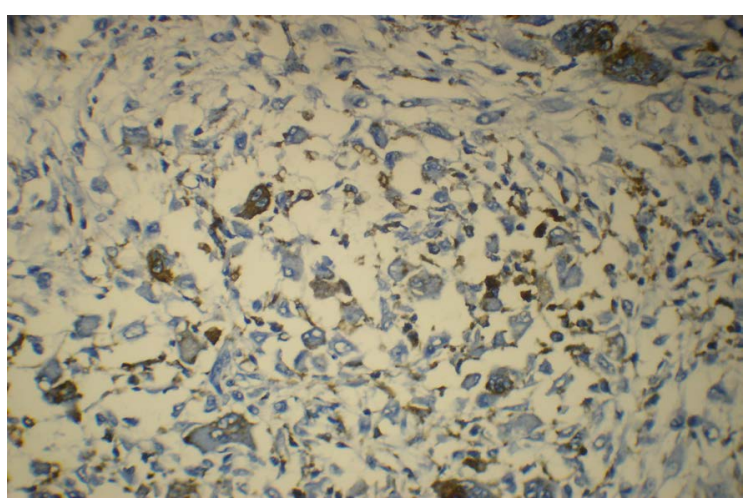

(b)

Figure 2. (a) This haematoxylin and eosin stained section shows a lesion composed of sheets of histiocytic cells with abundant cytoplasm and large vesicular nuclei with scattered multinucleated giant cells having similar nuclear and cytoplasmic appearance. These are supported by fibroconnective tissue stroma. No evidence of malignancy is seen. (b) This section shows the lesion stained with immunohistochemical staining for CD 68. The Histiocytes were stained positive and marked with brown color.

\section{Discussion}

In 1941, Jaffe et al. defined pigmented villonodular synovitis, bursitis and tenosynovitis as yellow-brown villous or nodular, tumor like lesions containing closely compacted polyhedral cells, multinucleated giant cells, lipoid cells and hemosiderin containing cells [2]. It primarily affects the major joint and $80 \%$ lesions are located in the knee. Other sites include hip, ankle, foot, hand, elbow and shoulder. PVNS of temporomandibular joint is rare [4].

These lesions can be classified as localized and diffuse type. Diffuse type has widespread involvement of synovium. The disease is twice more common in females as compared to males. The etiology is not clear. Jaffe proposed an inflammatory etiology. Other proposed etiologies are trauma, neoplasm [5] and abnormal lipid metabolism. Several chromosomal abnormalities have been reported to be associated with PVNS. Fletcher et al. [6] used FISH to demonstrate trisomy 7 in both cultured and uncultured PVNS cells. However other diseases like osteoarthritis, hemorrhagic synovitis and rheumatoid arthritis may contain cells with trisomy 7.

Lapayowker et al. [7] first reported 2 cases of PVNS in temporomandibular joint in 1973. PVNS usually presents as painless slow growing pre-auricular mass. Other common symptoms include pain and or swelling in temporomandibular joint, trismus, hearing loss and facial paresis. Our case presented with pain and unilateral decreased hearing. FNAC is a useful method to establish a diagnosis in cases presenting as pre-auricular facial swelling.

CT scan clearly showed areas of bone erosion and surgical resection was done till what appeared to be normal bone. This would classify the case as diffuse type tenosynovitis. CT scan defines the extent of the tumor because it has lower attenuation values than the surrounding muscles and CT scan also enhances the thickened synovium. PVNS typically demonstrate low signal intensity because of the presence of hemosiderin. The histopathology reports share the same features as that reported in the literature with CD 68 positivity on immunohistochemistry. On microscopy, PVNS is characterized by the presence of hemosiderin-laden, multinucleated, giant cells. In addition lipid-laden macrophages, fibroblasts and other large polyhedral-shaped mononuclear cells are present, they have abundant cytoplasm and possess oval nuclei. Hemosiderin is also found within the surrounding tissues. The ubiquitous presence of hemosiderin lends the tissue a characteristic pigmented appearance. The lesions tend to be hypervascular and demonstrate synovial hyperplasia.

The differential diagnosis of this lesion includes giant cell reparative granuloma, giant cell tumor, and chondroblastoma. Histopathologically, giant cell reparative granuloma has perivascular hemorrhage with clustering of giant cells around the hemosiderin deposition, whereas in giant cell tumor, there is usually uniform distribution of giant cells and hemosiderin deposits are rare. The background stroma of giant cell tumor granuloma consists of fibroblast like, tapered spindle cells and dense scar like collagen compared with the usual plump, oval cells in giant cell tumor [8].

Immunohistochemistry differentiates the PVNS from chondroblastoma as PVNS is CD68 positive and chon- 
droblastoma is S-100 positive [6].

The aggressive resection has been advocated in previous literature with long term radiological follow up with MRI. The recurrence rate has been reported ranging from $40 \%$ to $60 \%$ in cases of extra articular PVNS [8]. Radiotherapy is generally reserved for recurrent or incompletely resectable disease.

O' Sullivan et al reported 41 patients with PVNS of the knee treated with RT and recommended gross total resection followed by moderate-dose RT [9].

Blanco et al. conducted a prospective study on 22 patients with previously untreated diffuse PVNS of the knee treated with combined partial arthroscopic synovectomy and RT and reported a improvement in symptoms of joint stiffness and pain in $86 \%$ of cases [10].

\section{Conclusion}

Giant cell tenosynovitis of temporomandibular joint is a rare entity that may present as a destructive lesion. The treatment is an aggressive surgical resection of the disease and due to its high recurrence rate, regular follow up with imaging is mandatory.

\section{References}

[1] Chassaignac, E.P. (1852) Cancer de la gaine des tendons. Gazette des Hopitaux Civils et Militaires, 25, 185-186.

[2] Jaffe, H.L. (1953) Giant Cell Reparative Granuloma, Traumatic Bone Cyst, and Fibrous (Fibro-Osseous) Dysplasia of the Jaw Bones. Oral Surgery, Oral Medicine, Oral Pathology, 6, 159-175. http://dx.doi.org/10.1016/0030-4220(53)90151-0

[3] Cai, J., Cai, Z. and Gao, Y. (2011) Pigmented Villonodular Synovitis of the Temporomandibular Joint: A Case Report and the Literature Review. International Journal of Oral \& Maxillofacial Surgery, 40, 1314-1322. http://dx.doi.org/10.1016/j.ijom.2011.03.003

[4] Franchi, A., Frosini, P. and Santoro, R. (1994) Pigmented Villonodular Synovitis of the Temporomandibular Joint: Report of a Case. Journal of Laryngology and Otology, 108,166-167. http://dx.doi.org/10.1017/S0022215100126192

[5] Choong, P.F., et al. (1998) Pigmented Villonodular Synovitis. Monoclonality and Metastasis—A Case for Neoplastic Origin? Journal of Laryngology and Otology, 112, 182-185.

[6] Fletcher, J.A., Henkle, C., Atkins, L., Rosenberg, A.E. and Morton, C.C. (1992) Trisomy 5 and Trisomy 7 Are Nonrandom Aberrations in Pigmented Villonodular Synovitis: Confirmation of Trisomy 7 in Uncultured Cells. Genes Chromosomes Cancer, 4, 264-266. http://dx.doi.org/10.1002/gcc.2870040312

[7] Lapayowker, M.S., Miller, W.T., Levy, W.M. and Harwick, R.D. (1973) Pigmented Villonodular Synovitis of the Temporomandibular Joint. Radiology, 108, 313-316. http://dx.doi.org/10.1148/108.2.313

[8] Silvers, A.R., Som, P.M., Brandwein, M., Chong, J.L. and Shah, D. (1996) The Role of Imaging in the Diagnosis of Giant Cell Tumor of the Skull Base. American Journal of Neuroradiology, 17, 1392-1395.

[9] O’Sullivan, T.J., Alport, E.C. and Whiston, H.G. (1984) Pigmented Villonodular Synovitis of the Temporomandibular Joint. Journal of Otolaryngology, 13, 123-126.

[10] Blanco, C.E., Leon, H.O. and Guthrie, T.B. (2001) Combined Partial Arthroscopic Synovectomy and Radiation Therapy for Diffuse Pigmented Villonodular Synovitis of the Knee. Arthroscopy, 17, 527-531. http://dx.doi.org/10.1053/jars.2001.24068 